Check for updates

Cite this: Chem. Commun., 2020, 56, 12861

Received 22nd June 2020,

Accepted 10th September 2020

DOI: $10.1039 / \mathrm{d} 0 \mathrm{cc} 04337 \mathrm{k}$

rsc.li/chemcomm

\section{A novel, rationally designed lanthanoid chelating tag delivers large paramagnetic structural restraints for biomolecular NMR $\dagger$}

\author{
Daniel Joss, (D) Florine Winter and Daniel Häussinger (D) *
}

\begin{abstract}
Herein, a novel and rationally designed ortho-substituted pyridine activator is reported that reacts rapidly and selectively with cysteine thiols. It forms reduction-stable conjugates and induces large pseudocontact shifts, residual dipolar couplings and paramagnetic relaxation enhancement on both ubiquitin S57C and human carbonic anhydrase II S50C constructs under physiological conditions.
\end{abstract}

Paramagnetic effects induced by metal centres with anisotropic distribution of unpaired electrons on biomacromolecules, ${ }^{1,2}$ e.g. lanthanoid ions complexed with suitable chelators for attachment, provide a unique and precise tool for the study of the properties of biomacromolecules by solution NMR. ${ }^{3-6}$ More specifically, lanthanoid chelating tags (LCT) induce longrange restraints that provide the unique opportunity to elucidate the structure of complexes, dynamics and interactions of biomacromolecules and ligands. ${ }^{7-16}$ In order to induce large paramagnetic effects, i.e. large pseudocontact shifts (PCS), residual dipolar couplings (RDC) and paramagnetic relaxation enhancement (PRE), rigid immobilization of the lanthanoid chelator on the surface of the biomacromolecule of interest is crucial. ${ }^{5,6}$ Conformational and positional invariant LCTs are ideally suited for monitoring protein interactions, as they can be placed far away from the interface and nevertheless provide accurate spatial information up to $200 \AA$.

Earlier approaches to suppress the translational and rotational freedom of the chelator on the surface of the protein, and hence to induce long-range restraints in solution, include: (1) two linker moieties attached to a double cysteine mutant, ${ }^{17-19}$ (2) restriction of the translational and rotational mobility, ${ }^{20-22}$ (3) placement of bulky groups on the macrocyclic ring scaffold. ${ }^{22,23}$

In order to restrict the remaining rotational averaging by para-substituted linker moieties, ${ }^{20,21}$ we rationally designed a novel, ortho-substituted pyridine activator that leads to a

Department of Chemistry, University of Basel, St. Johanns-Ring 19, Basel 4056, Switzerland. E-mail: daniel.haeussinger@unibas.ch

† Electronic supplementary information (ESI) available. See DOI: 10.1039/ d0cc04337k hampered rotation around the $\mathrm{S}_{\text {cysteine }}-\mathrm{C}_{\text {pyridine }}$ bond and to a short, reduction-stable linkage between the LCT and the biomacromolecule (Fig. 1). As carved out during the design process, cysteine-selective and rapid conjugation in ortho-position requires a very delicate tuning of an electron-withdrawing $\pi$-acceptor type functional group and a suitable leaving group in order to balance high reactivity, potential hydrolysis and steric demands of the incoming cysteine thiol as nucleophile. During the nucleophilic aromatic substitution tagging reaction, a nitro substituent in meta-position stabilises the Meisenheimer complex intermediate ${ }^{24}$ and, in combination with a methylsulphone leaving group, allows for fast and selective ligation of the LCT with a cysteine residue of the targeted biomacromolecule.

The seven methyl groups on the cyclen-based ring scaffold of the proposed LCT (Ln- $\left(2 R, 2^{\prime} R, 2^{\prime \prime} R\right)-2,2^{\prime}, 2^{\prime \prime}-((2 S, 5 S, 8 S, 11 S)$ 2,5,8,11-tetramethyl-10-((6-(methylsulphonyl)-5-nitropyridin-2-yl) methyl)-1,4,7,10-tetraazacyclododecane-1,4,7-triyl)tripropanoate = Ln-M7-Nitro), and on the pendant carboxylate side arms provide a significant rigidification of the chelator. ${ }^{25-28}$ Reduction-stable thioether linkages of LCT-protein were earlier shown to provide an attachment suitable for acquisition of paramagnetic restraints by in-cell NMR. ${ }^{12,13}$

In order to demonstrate the applicability of our proposed approach, we synthesized paramagnetic thulium, dysprosium,

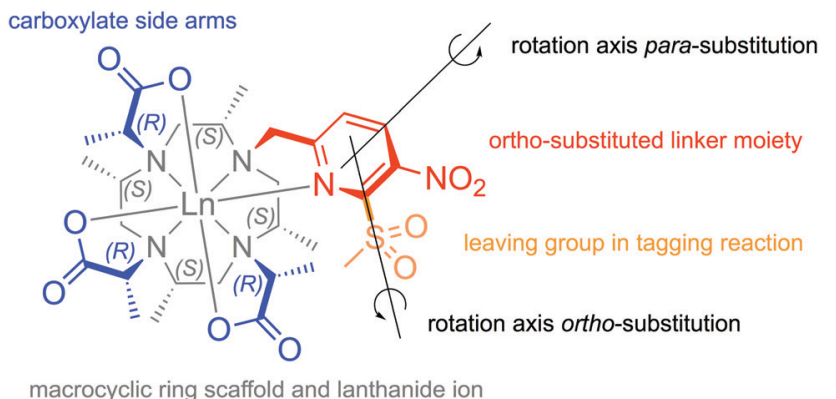

Fig. 1 Structure of Ln-M7-Nitro in $\Lambda(\delta \delta \delta \delta)$ conformation and indication of the important parts of the chelator. 


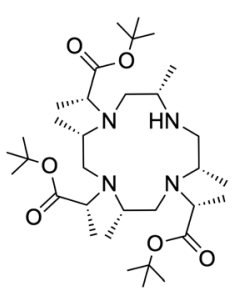

2

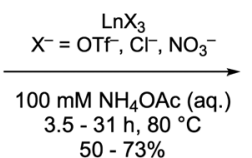<smiles>CSc1nc(CBr)ccc1[N+](=O)[O-]</smiles>

1, (2.0 eq.)

$\mathrm{K}_{2} \mathrm{CO}_{3}$ (5.0 eq.)

ACN, $1 \mathrm{~d}, \mathrm{RT}$ $93 \%$

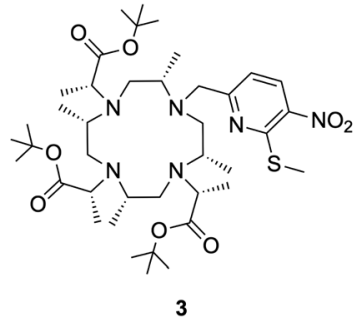

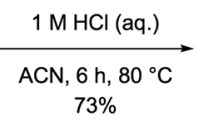

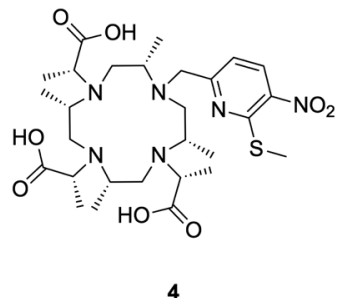
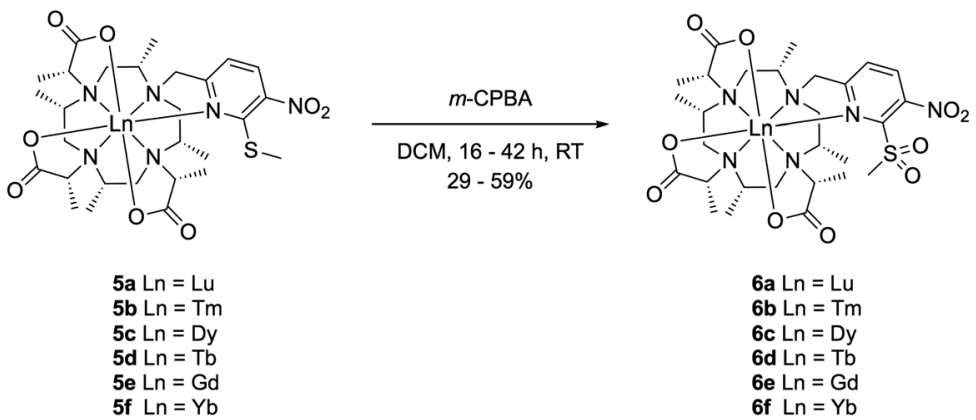

6a $L n=L u$
6b $L n=T m$

$6 c \ln =\mathrm{Dy}$

6c $\operatorname{Ln}=D y$

$6 d \operatorname{Ln}=T b$

6e $\operatorname{Ln}=\mathrm{Gd}$
6f $\operatorname{Ln}=Y b$

Fig. 2 Synthetic route to Ln-M7-Nitro starting from sevenfold methyl-substituted cyclen precursor 2 via alkylation, deprotection, metalation and oxidation.

terbium, ytterbium and gadolinium complexes in combination with the lutetium complex as diamagnetic reference and investigated their potential for the generation of PCSs (position of amide groups in 3D space), RDCs (orientation of the amide $\mathrm{N}-\mathrm{H}$ vectors in space) and PRE (distance of amide protons from the paramagnetic centre) on both ubiquitin S57C (9 kDa) and human carbonic anhydrase II S50C (hCA II, $30 \mathrm{kDa}$ ) constructs.

With the idea of the installation of a leaving group in the ortho-position of the pyridine moiety of the envisioned LCT in mind, a suitable bromopyridine linker precursor $\mathbf{1}$ was synthesized starting from the commercially available 2-chloro6-methyl-3-nitropyridine (ESI, $\dagger$ pp. 3-4). A sevenfold methylsubstituted cyclen precursor with three side arms already installed (2) was then reacted with the brominated linker precursor 1 in an alkylation reaction (Fig. 2). The precursor of the LCT with all four side arms installed (3) was then deprotected by heating of the compound with hydrochloric acid in acetonitrile to give the free ligand 4 . Subsequently, the chelator was loaded with lanthanoid ions suitable for the investigation of paramagnetic effects on biomacromolecules (5) and the leaving group was activated by oxidation of the thioether to the methylsulphone (6).

In order to test the magnitude of the induced PCS and RDC effects of Ln-M7-Nitro on ubiquitin S57C and selectively ${ }^{15} \mathrm{~N}$ leucine labelled hCA II S50C protein constructs, paramagnetic $\mathrm{Tm}$-, Dy-, Tb- and Yb-loaded complexes were conjugated to the

Table 1 Induced axial and rhombic components of the paramagnetic susceptibility tensors $\left(\Delta \chi_{\text {ax }}\right.$ and $\Delta \chi_{\text {rh }}$, in $\left.10^{-32} \mathrm{~m}^{3}\right)$, metal position in PDB coordinate frame $\left(X_{\text {metal, }} Y_{\text {metal, }} Z_{\text {metal, }}\right.$ in $\left.\AA\right)$, Euler angles $\left(\alpha, \beta, \gamma\right.$, in $\left.{ }^{\circ}\right)$ and quality factor $(Q$, mathematical definition in ESI, p. 1) on ubiquitin S57C (pH 6.0) and selectively ${ }^{15} \mathrm{~N}$ leucine labelled hCA II S50C (pH 6.8) at 298 K. PCS data was fitted using Numbat, ${ }^{32}$ while RDC tensors were obtained with Fanten. ${ }^{33}$ A detailed table with single and joint fits of PCS/RDC is available in the ESI (Tables S17 and S18)

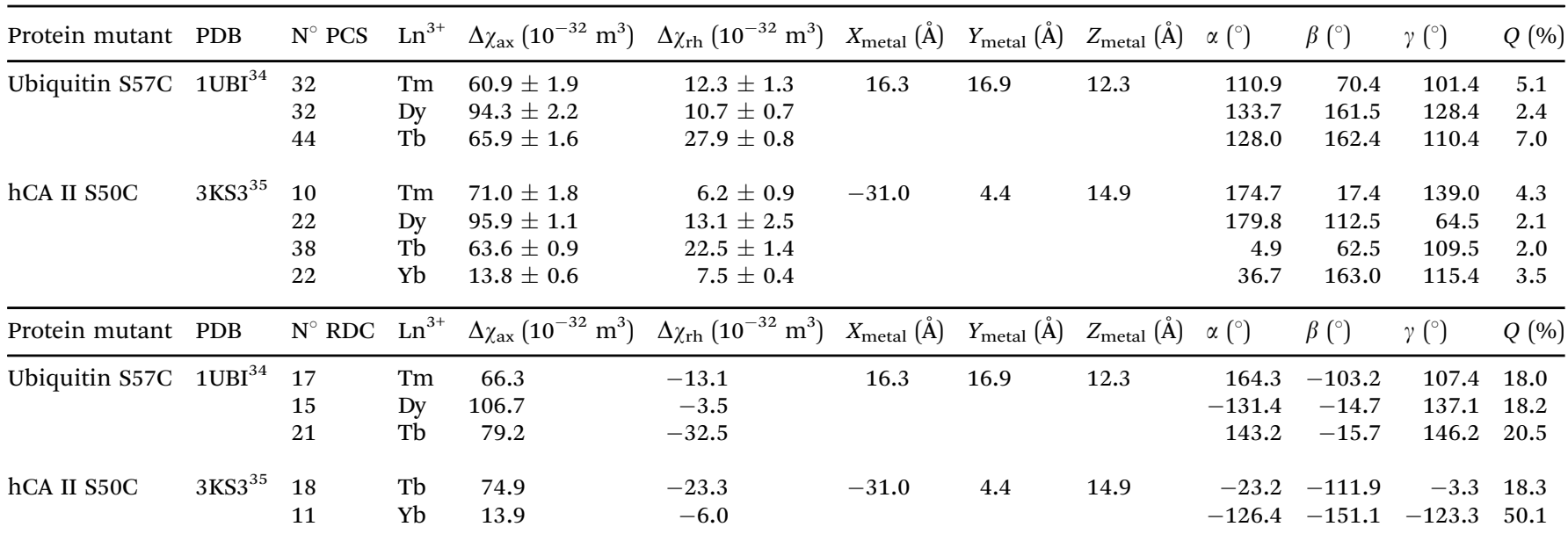


solvent exposed single cysteine residues on the protein constructs, whereas the Lu-complex was used as diamagnetic reference when conjugated to the protein. Subsequently, ${ }^{1} \mathrm{H}^{15}{ }^{15}$ HSQC (acquisition of PCSs) and ${ }^{1} \mathrm{H}-{ }^{15} \mathrm{~N}$ HSQC IPAP (acquisition of RDCs, no decoupling in the ${ }^{15} \mathrm{~N}$ dimension) experiments were acquired. Ln-M7-Nitro was thereby shown to induce anisotropy parameters on ubiquitin S57C of up to $\Delta \chi_{\mathrm{ax}}=94.3 \times 10^{-32} \mathrm{~m}^{3}$ for Dy-, $\Delta \chi_{\mathrm{ax}}=65.9 \times 10^{-32} \mathrm{~m}^{3}$ for $\mathrm{Tb}-$ and $\Delta \chi_{\text {ax }}=60.9 \times 10^{-32} \mathrm{~m}^{3}$ for Tm-M7-Nitro (Table 1). When compared to other LCTs, the anisotropy parameters induced by Ln-M7-Nitro are exceedingly large and the value for the Dy-loaded chelator attached to ubiquitin S57C constitutes an unprecedented value of $\Delta \chi_{\mathrm{ax}}$ for an LCT-protein construct. ${ }^{17,19,20,22,29}$ The obtained $Q$-factors and the distance of the fitted lanthanoid metal centre to the $\mathrm{C}_{\mathrm{beta}}$-carbon of the cysteine residue $(6.9 \AA$ ) indicate excellent fits. Notably, RDCs up to $41.3 \mathrm{~Hz}$ were obtained for the Dy-loaded chelator, while RDCs of up to $35.9 \mathrm{~Hz}$ were obtained using the Tb complex (Tables S11 and S12, ESI $\dagger$ ). In order to confirm the results obtained on ubiquitin S57C (9 kDa) and to extend our methodology to a larger protein, selectively ${ }^{15} \mathrm{~N}$ leucine labelled hCA II S50C $(30 \mathrm{kDa})$ with a single solvent exposed cysteine was chosen as suitable target. Similar anisotropy parameters as for ubiquitin S57C were found (Table 1) and the $\mathrm{Ln}-\mathrm{C}_{\text {beta,cys }}$ distance of $7.1 \AA$ indicated an excellent quality of the obtained fits. As can be seen from the anisotropy parameters depicted as isosurfaces (Fig. 3), the properties of the induced effects match for the pairs Dy and $\mathrm{Tb}$ as well as for $\mathrm{Tm}$ and $\mathrm{Yb}$ - intrinsic properties of the lanthanoids that were described in literature. ${ }^{5}$ When compared to seven-fold methyl substituted, pyridine derived LCTs, as e.g. Tm-M7FPy-DOTA ${ }^{21}$ attached to ubiquitin S57C, Tm-M7-Nitro shows a superior performance, which can most likely be attributed to the switch of the ligation site on the pyridine linker moiety from the para- to the ortho-position and therefore to an increased rotational and translational rigidity of the LCT relative to the protein surface. Since PCSs and RDCs are susceptible to different motional averaging mechanisms, a joint fit of PCSs and RDCs should result in the same tensors as the individual fits in case of a non-mobile LCT. ${ }^{30,31}$ We were delighted to find that $\Delta \chi_{\text {ax }}$ for the combined PCS/RDC fit agreed on average with the PCS fit within 5 and $9 \%$ for ubiquitin and hCA II, respectively, whereas the agreement with the RDC fit was even better ( 0.3 and $1 \%$, see Table S18, ESI $\dagger$ ). Ln-M7-Nitro might, therefore, be also useful to detect dynamics. The moderate Curie line broadening of approx. only $20 \mathrm{~Hz}$ in the case of hCA II, observed at $600 \mathrm{MHz}$ in $24 \AA$ distance from the lanthanoid, holds great promise also for applications at ultrahigh fields (Fig. S40, ESI $\dagger$ ).

Due to the stabilization of the intermediate Meisenheimer complex $^{24}$ during the ligation reaction by the newly developed activator, Ln-M7-Nitro provides a fast, quantitative and therefore clean ligation to the protein. As confirmed by ESI-HRMS, a ligation yield of $>95 \%$ is already observed after $30 \mathrm{~min}$ at room temperature (Fig. 4). The 3-nitro-substituted 2-(methylsulphonyl)pyridine constitutes a novel, highly reactive and selective moiety for tagging of cysteines in biomacromolecules under close to physiological conditions (highly diluted $(\sim 100 \mu \mathrm{M})$, aqueous buffer, pH 7.0). While the methylsulphonyl leaving group shows a suitable balance in terms of reactivity and selectivity, a fluorine leaving group led to hydrolysis and chlorine showed no reaction.

Besides the favourable properties of Ln-M7-Nitro for the generation of anisotropic paramagnetic effects, we were curious about the properties of Ln-M7-Nitro as PRE tag. PRE is an isotropic effect that enhances the relaxation of spins in vicinity to the paramagnetic metal centre and causes thereby line broadening, which can be quantified by plotting the intensity ratio of paramagnetic and diamagnetic peaks $v s$. the distance of the amide proton to the metal centre. Upon attachment of the Gd complex of the newly developed LCT to both ubiquitin S57C
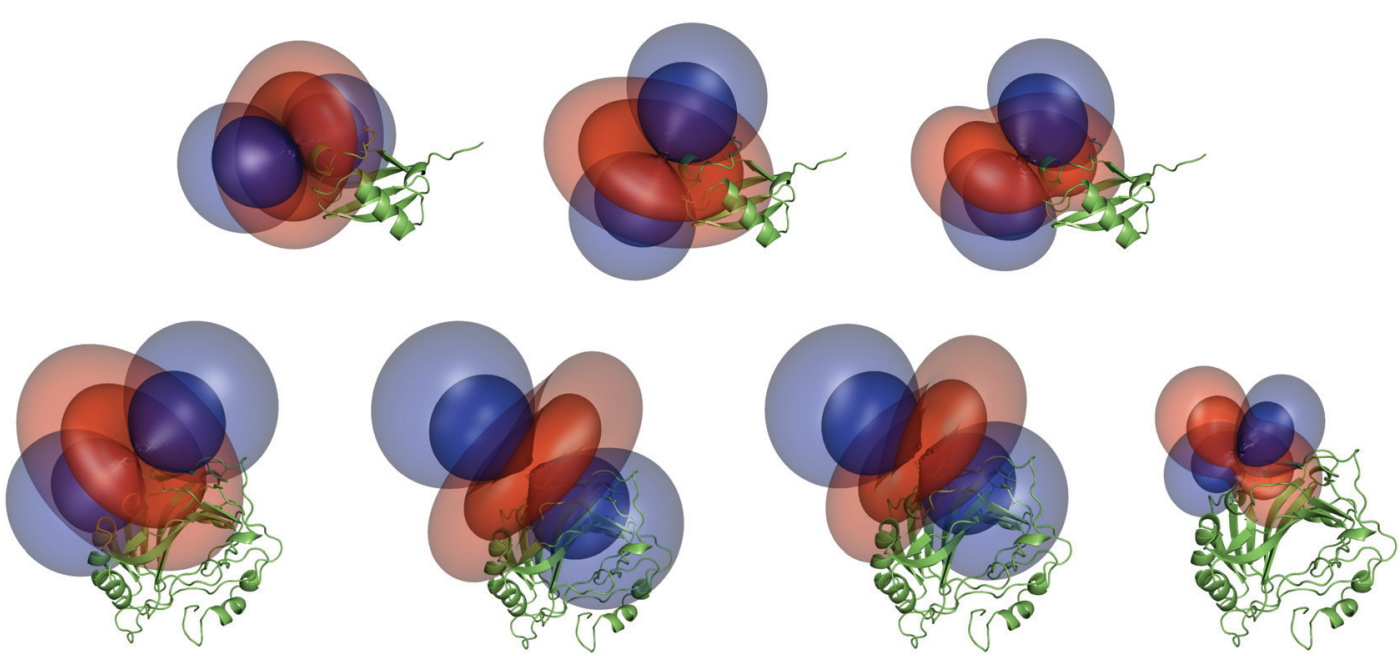

Fig. 3 Anisotropy parameters induced by Ln-M7-Nitro on ubiquitin S57C (top) and selectively ${ }^{15} \mathrm{~N}$ leucine labelled hCA II S50C (bottom) depicted as isosurfaces with a given shift in ppm (generated using Numbat ${ }^{32}$ ). Top (from left to right): Tm-, Dy- and Tb-M7-Nitro-Ub ${ }^{\mathrm{S57C}}$ (inner layer: 4.0 ppm, outer layer: 1.5 ppm). Bottom (from left to right): Tm-, Dy-, Tb- and Yb-M7-Nitro attached to selectively ${ }^{15} \mathrm{~N}$ leucine labelled hCA II S50C (inner layer: 3.0 ppm, outer layer: $0.8 \mathrm{ppm})$. 


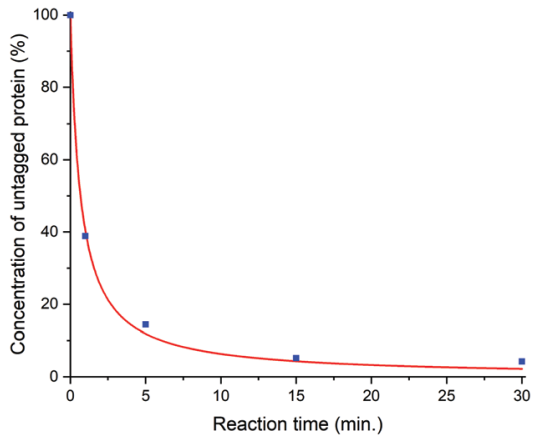

Fig. 4 Kinetics of the tagging reaction of monomeric ubiquitin S57C $(90 \mu \mathrm{M})$ with Lu-M7-Nitro $(540 \mu \mathrm{M})$ in phosphate buffer $(10 \mathrm{mM}, \mathrm{pH} 7.0$, $0.2 \mathrm{mM}$ TCEP) followed by ESI-HRMS. The experimental data points were fitted with the equation for second order kinetics [Ubi] $=\left(k \cdot t+1 /[\mathrm{Ubi}]_{t=0}\right)^{-1}$ to give $k=274.5 \mathrm{M}^{-1} \mathrm{~s}^{-1}$. A comparison of Ln-M7-Nitro and previously reported LCTs is shown in Fig. S41 (ESI†).

and hCA II S50C, strong PREs were detected in ${ }^{1} \mathrm{H}-{ }^{15} \mathrm{~N}$ HSQC experiments and evaluated with respect to their distance dependence, the amino acid sequence of the protein and the theoretically predicted values for an LCT-protein construct with the same molecular weight (Fig. S9-S12, ESI $\dagger$ ). ${ }^{36}$ PRE was previously used to resolve structures and interactions of biomacromolecules in solution. ${ }^{37}$

To conclude, a novel, rationally designed ortho-substituted pyridine activator was developed that delivers an LCT with unprecedented paramagnetic properties and, thereby, allows for acquisition of experimental structural restraints for the investigation of structure and dynamics of biomacromolecules and their complexes via PCSs, RDCs and PREs. The fast and clean ligation reaction of the new activator in combination with the strong, induced paramagnetic effects render Ln-M7-Nitro as an ideal LCT for challenging applications.

The Chemistry Department of the University of Basel and the SNSF grant 200021_130263 are acknowledged for financial support. Biological structures were generated using the open source software PyMOL. C. E. Housecroft, E. C. Constable, T. Müntener, R. Vogel and P. Rieder are acknowledged for helpful discussions and S. Fischer for involvement in synthetic side projects.

\section{Conflicts of interest}

There are no conflicts to declare.

\section{Notes and references}

1 I. Bertini, C. Luchinat, G. Parigi and R. Pierattelli, ChemBioChem, 2005, 6, 1536-1549.

2 J. H. Prestegard, H. M. Al-Hashimi and J. R. Tolman, Q. Rev. Biophys., 2000, 33, 371-424.

3 J. Koehler and J. Meiler, Prog. Nucl. Magn. Reson. Spectrosc., 2011, 59, 360-389.

4 W.-M. Liu, M. Overhand and M. Ubbink, Coord. Chem. Rev., 2014, 273-274, 2-12.
5 C. Nitsche and G. Otting, Prog. Nucl. Magn. Reson. Spectrosc., 2017, 98-99, 20-49.

6 D. Joss and D. Häussinger, Prog. Nucl. Magn. Reson. Spectrosc., 2019, 114-115, 284-312.

7 G. Pintacuda, M. John, X.-C. Su and G. Otting, Acc. Chem. Res., 2007, 40, 206-212.

8 J.-Y. Guan, P. H. J. Keizers, W.-M. Liu, F. Löhr, S. P. Skinner, E. A. Heeneman, H. Schwalbe, M. Ubbink and G. Siegal, J. Am. Chem. Soc., 2013, 135, 5859-5868.

9 C. Göbl, T. Madl, B. Simon and M. Sattler, Prog. Nucl. Magn. Reson. Spectrosc., 2014, 80, 26-63.

10 K. D. Brewer, T. Bacaj, A. Cavalli, C. Camilloni, J. D. Swarbrick, J. Liu, A. Zhou, P. Zhou, N. Barlow, J. Xu, A. B. Seven, E. A. Prinslow, R. Voleti, D. Häussinger, A. M. J. J. Bonvin, D. R. Tomchick, M. Vendruscolo, B. Graham, T. C. Südhof and J. Rizo, Nat. Struct. Mol. Biol., 2015, 22, 555-564.

11 T. Saio, K. Ogura, H. Kumeta, Y. Kobashigawa, K. Shimizu, M. Yokochi, K. Kodama, H. Yamaguchi, H. Tsujishita and F. Inagaki, Sci. Rep., 2015, 5, 16685.

12 T. Müntener, D. Häussinger, P. Selenko and F.-X. Theillet, J. Phys. Chem. Lett., 2016, 7, 2821-2825.

13 B.-B. Pan, F. Yang, Y. Ye, Q. Wu, C. Li, T. Huber and X.-C. Su, Chem. Commun., 2016, 52, 10237-10240.

14 K. Zimmermann, D. Joss, T. Müntener, E. S. Nogueira, M. Schäfer, L. Knörr, F. W. Monnard and D. Häussinger, Chem. Sci., 2019, 10, 5064-5072.

15 D. Joss, R. Vogel and D. Häussinger, Ref. Mod. in Chem, Mol. Sci. and Chem. Eng., 2020, DOI: 10.1016/B978-0-12-409547-2.14848-6.

16 C. A. Barnes, Y. Shen, J. Ying, Y. Takagi, D. A. Torchia, J. R. Sellers and A. Bax, J. Am. Chem. Soc., 2019, 141, 9004-9017.

17 P. H. Keizers, A. Saragliadis, Y. Hiruma, M. Overhand and M. Ubbink, J. Am. Chem. Soc., 2008, 130, 14802-14812.

18 W.-M. Liu, P. H. J. Keizers, M. A. S. Hass, A. Blok, M. Timmer, A. J. C. Sarris, M. Overhand and M. Ubbink, J. Am. Chem. Soc., 2012, 134, 17306-17313.

19 M. D. Lee, M. L. Dennis, B. Graham and J. D. Swarbrick, Chem. Commun., 2017, 53, 13205-13208.

20 F. Yang, X. Wang, B.-B. Pan and X.-C. Su, Chem. Commun., 2016, 52, 11535-11538.

21 T. Müntener, J. Kottelat, A. Huber and D. Häussinger, Bioconjugate Chem., 2018, 29, 3344-3351.

22 D. Joss and D. Häussinger, Chem. Commun., 2019, 55, 10543-10546.

23 D. Joss, M.-S. Bertrams and D. Häussinger, Chem. - Eur. J., 2019, 25, 11910-11917.

24 C. N. Neumann, J. M. Hooker and T. Ritter, Nature, 2016, 534, 369-373.

25 D. Häussinger, J.-R. Huang and S. Grzesiek, J. Am. Chem. Soc., 2009, 131, 14761-14767.

26 A. C. L. Opina, M. Strickland, Y.-S. Lee, N. Tjandra, R. A. Byrd, R. E. Swenson and O. Vasalatiy, Dalton Trans., 2016, 45, 4673-4687.

27 D. Joss, R. M. Walliser, K. Zimmermann and D. Häussinger, J. Biomol. NMR, 2018, 29-38.

28 D. Parker, R. S. Dickins, H. Puschmann, C. Crossland and J. A. K. Howard, Chem. Rev., 2002, 102, 1977-2010.

29 F. Peters, M. Maestre-Martinez, A. Leonov, L. Kovacic, S. Becker, R. Boelens and C. Griesinger, J. Biomol. NMR, 2011, 51, 329-337.

30 D. Shishmarev and G. Otting, J. Biomol. NMR, 2013, 56, 203-216.

31 I. Bertini, C. Luchinat, G. Parigi and E. Ravera, NMR of Paramagnetic Molecules, Elsevier, Boston, 2nd edn, 2017, pp. 277-312.

32 C. Schmitz, M. J. Stanton-Cook, X.-C. Su, G. Otting and T. Huber, J. Biomol. NMR, 2008, 41, 179.

33 M. Rinaldelli, A. Carlon, E. Ravera, G. Parigi and C. Luchinat, J. Biomol. NMR, 2015, 61, 21-34.

34 R. Ramage, J. Green, T. W. Muir, O. M. Ogunjobi, S. Love and K. Shaw, Biochem. J., 1994, 299(Pt 1), 151-158.

35 B. S. Avvaru, C. U. Kim, K. H. Sippel, S. M. Gruner, M. Agbandje-McKenna, D. N. Silverman and R. McKenna, Biochemistry, 2010, 49, 249-251.

36 J. L. Battiste and G. Wagner, Biochemistry, 2000, 39, 5355-5365.

37 G. M. Clore and J. Iwahara, Chem. Rev., 2009, 109, 4108-4139. 